\title{
Receptors for gammaglobulin in the central and peripheral nervous system
}

\author{
C Vedeler, E Ulvestad, H Nyland, R Matre, J A Aarli
}

A heterogeneous group of receptors binding the $\mathrm{Fc}$ region of immunoglobulin (Ig), Fc receptors provide important links between the cellular and the humoral branches of the immune system. The members of this receptor group, specific for essentially all the Ig isotypes, are expressed on a variety of cells and mediate multiple important functions.

Receptors for IgG (Fc $\gamma$ R), a subgroup within the larger group of Fc receptors, belong to the Ig supergene family. The receptors have repeating extracellular domains, a membrane spanning portion and a cytoplasmic tail and the genes encoding the receptors have been assigned to chromosome $1 .^{1}$

When $\mathrm{Fc} \gamma \mathrm{R}$ interact with the ligand, causing crosslinking of the receptors, a variety of biological responses are triggered. These include phagocytosis, antibody-dependent cellular cytotoxicity (ADCC), release of cytotoxic and inflammatory mediators, enhanced antigen presentation, immune regulation and transfer of IgG. For immune regulation, it has been shown that the Fc $\gamma$ R can interfere with maturation of $T$ and $B$ lymphocytes as well as antibody production in an isotypic specific way. ${ }^{1}$

Three major classes of leukocyte $F c \gamma R$ are currently recognised on the basis of ligand affinity, reactivity with monoclonal antibodies (mabs) and cloning of complementary DNA (cDNA). ${ }^{1}$ Fc $\gamma$ RI (CD64) are $70 \mathrm{kDa}$ molecules expressed on monocytes and macrophages with high affinity for IgG and can be induced on neutrophils by interferon- $\gamma$ (IFN- $\gamma$ ). Fc $\gamma$ RII (CD32) have a molecular weight of $40 \mathrm{kDa}$ and are encoded by three genes. Fc $\gamma$ RIIB are expressed on lymphocytes, Fc $\gamma$ RIIA and Fc $\gamma$ RIIC are expressed on neutrophils, while monocytes and macrophages express all three variations. Fc $\gamma$ RIII (CD16), of molecular weight between 45-80 $\mathrm{kDa}$, have two distinct forms. Fc $\gamma \mathrm{RIIIB}$ found on neutrophils are anchored to the membrane by glycosyl-phosphatidyl inositol whereas FcrRIIIA expressed on natural killer (NK) cells and macrophages are transmembrane proteins. Both Fc $\gamma$ RII and Fc $\gamma$ RIII have low affinity for IgG. Current information indicates that the three classes of $F c \gamma R$ do not perform discrete tasks. Rather, their functions seem dictated by the cell type on which they are displayed.

Fc $\gamma \mathbf{R}$ are also present on non-lymphoid cells in different organs, for example on trophoblasts and endothelial cells in human placenta $^{2}$ and on keratinocytes in human skin. ${ }^{3}$ In this review we report the presence and possible functions of $F c \gamma R$ in the human nervous system.

\section{$F c \gamma R$ in the central nervous system}

Fc $\gamma R$ have been demonstrated on cells in the choroid plexus, arachnoid granulations, leptomeninges, ${ }^{4}$ on perivascular macrophages, microglia and on endothelial cells. ${ }^{5} \mathrm{~F} \gamma \mathrm{R}$ have also been found on microglia in culture. ${ }^{67}$ The receptors were demonstrated by haemadsorption of IgG-coated indicator cells, by binding of soluble immune complexes of horseradish peroxidase (HRP) anti-HRP and serologically using mabs. Microglia and perivascular macrophages were stained by mabs to $\mathrm{F} c \gamma \mathrm{RI}$, Fc $\gamma$ RII and Fc $\gamma$ RIII, whereas endothelial cells were stained by anti-Fc $\gamma$ RIII mabs only. ${ }^{5}$ Oligodendrocytes, astrocytes and neurons do not express Fc $\gamma$ R. ${ }^{5}$ Recently, Fc $\gamma$ RIII mRNA was demonstrated in microglia using in situ hybridisation. ${ }^{6}$ The same radiolabelled cDNA probe for Fc $\gamma$ RIII hybridised with a $1.4 \mathrm{~kb}$ RNA band in Northern blots prepared from total RNA from brain, indicating that the receptors are produced in the CNS. ${ }^{6}$

\section{$\mathbf{F c} \gamma \mathbf{R}$ in the peripheral nervous system} F $\gamma \mathbf{R}$ have also been demonstrated on Schwann cells, perineurial cells, endothelial cells and on scattered endoneurial macrophages. ${ }^{89}$ The receptors were found on the surface membrane, inner membrane (axolemma) and on vesicles within the cytoplasm of Schwann cells by electron microscopy..$^{11}$ Schwann cells in culture apparently lose their $\mathrm{F} c \gamma \mathrm{R}$ expression. ${ }^{12}$ Whether this is due to dedifferentiation of the cells or to loss of Schwann cell-axon interaction is not known. $\mathrm{F} c \gamma \mathrm{R}$ have been recognised in fetal nerves at approximately 10 weeks of gestation ${ }^{12}$ showing that the receptors are an innate component of the PNS. Mabs against Fc $\gamma$ RI, Fc $\gamma$ RII and Fc $\gamma$ RIII stained scattered endoneurial macrophages, whereas only mabs against low affinity $F c \gamma R$ stained Schwann cells, perineurial cells and endothelial cells. ${ }^{9}$ A radiolabelled cDNA probe for Fc $\gamma$ RIII hybridised with a $1.4 \mathrm{~kb}$ RNA band in Northern blots prepared from total RNA from peripheral nerve. The steady state level of the $1.4 \mathrm{~kb} F \mathrm{~F} \gamma \mathrm{RIII}$ mRNA was found to be developmentally regulated by densitometry. ${ }^{13}$ In situ hybridisation experiments have demonstrated increased numbers of endoneurial Fc $\gamma$ RIII mRNA positive macrophages in Wallerian degeneration, ${ }^{13}$ and in experimental allergic neuritis (EAN). ${ }^{14}$

Functions of $F c \gamma R$ in the nervous system To date little is known about the functions of $\mathrm{F} c \gamma \mathrm{R}$ in the CNS and PNS. The Fc $\gamma \mathrm{R}$ in the 
choroid plexus and arachnoid granulations may be involved in the transcellular transport of IgG from blood to cerebrospinal fluid (CSF) and from CSF to blood, the same mechanism proposed for $\mathrm{F} c \gamma \mathrm{R}$ in the placenta transferring IgG from mother to fetus. ${ }^{2}$

$\mathrm{F} c \gamma \mathrm{R}$ on microglia mediate phagocytosis of IgG-coated particles, ADCC and oxidative burst. ${ }^{7}$ Crosslinking of microglial $\mathrm{Fc} \gamma \mathrm{R}$ may also induce production of inflammatory mediators such as interleukin- 1 , interleukin- 6 and tumour necrosis factor. Recently, it has been shown that $F c \gamma R$ expression is highly upregulated on perivascular macrophages and microglia within active multiple sclerosis (MS) lesions compared with Fc $\gamma \mathrm{R}$ expression on cells in the parenchyma outside the demyelinating lesions. ${ }^{5}$ Fc $\gamma \mathrm{R}$ therefore probably play an important role in myelin breakdown in MS. IFN- $\gamma$ greatly enhances microglia Fc $\gamma \mathrm{R}$ mediated responses. ${ }^{7}$ This is of particular interest since MS patients treated with IFN- $\gamma$ experience exacerbation. ${ }^{15}$ Fc $\gamma \mathbf{R}$ may also contribute to immune-mediated phagocytosis by leptomeningeal cells which have the potential to become phagocytic during pathological conditions. ${ }^{16}$

Immune-mediated phagocytosis and antigen presentation may also take place in the PNS, ${ }^{17} 18$ via $F c \gamma R$ on Schwann cells and on endoneurial macrophages. Increased number of macrophages participating in phagocytosis are found in Wallerian degeneration ${ }^{13}$ and in EAN. ${ }^{14}$ Whether crosslinking of $F c \gamma R$ on cells in the PNS also mediates release of various cytokines, as well as lysosomal enzymes, remains to be determined.

Fc $\gamma R$ on cells in the CNS and PNS may furthermore enhance infection of opsonised agents, such as HIV in microglia ${ }^{19}$ and $M$ leprae in Schwann cells. ${ }^{20}$ In addition, $F c \gamma R$ on endothelial cells may be involved in binding immune complexes and induce vasculitis.

Binding of IgG to $\mathrm{Fc} \gamma \mathrm{R}$ induces production of soluble $\mathrm{Fc} \gamma \mathrm{R}(\mathrm{sFc} \gamma \mathrm{R})$ in vitro. ${ }^{21}$ This may explain $\mathrm{sFc} \gamma \mathrm{R}$ intercellularly in MS lesions. $\mathrm{sFc} \gamma \mathrm{R}$ may neutralise possible hazardous autoantibodies by preventing membranebinding or by blocking the $\mathrm{C} 1 \mathrm{q}$ site which again would limit complement activation. Since $\mathrm{sFc} \gamma \mathrm{R}$ block in vitro IgG production, ${ }^{22}$ it is possible that soluble receptors also reduce the production of autoantibodies in the nervous system.

\section{Conclusions}

Fc $\gamma R$ are present on various cells in the CNS and PNS. The different biological functions of these receptors may be relevant in the pathogenesis of immunemediated diseases of the nervous system. Therapeutic trials with intravenous IgG have shown clinical improvement in patients with neurological diseases such as Guillain-Barré syndrome ${ }^{23}$ and chronic inflammatory demyelinating polyneuropathy. ${ }^{24}$ Recently, it has been shown that infusions of $\mathrm{Fc} \gamma$ fragments are beneficial in immune thrombocytopenic purpura, ${ }^{25}$ indicating that ligand binding to $\mathrm{Fc} \gamma \mathrm{R}$ may induce immuno-suppressive effects. This could occur systemically and locally in the nervous system through a damaged blood-brain or bloodnerve barrier. Binding of IgG Fc fragments to $\mathrm{Fc} \gamma \mathrm{R}$ in the CNS and PNS could: 1) block the various effects that are mediated by crosslinked $F c \gamma R$ such as phagocytosis, enhanced antigen presentation, ADCC and release of cytotoxic and inflammatory mediators; and 2) release $s F c \gamma R$ that may neutralise autoantibodies or immune complexes and downregulate a local Ig production.

1 van de Winkel JGJ, Capel PJA. Human IgG Fc receptor heterogeneity: molecular aspects and clinical implications. Immunol Today 1993;14:215-31.

2 Matre R. Similarities of Fc $\gamma$ receptors on trophoblasts and placental endothelial cells. Scand f Immunol 1977;6: 953-8.

3 Livden JK. Fc $\gamma$ receptors on keratinocytes in psoriasis. Arch Dermatol Res 1988;280:12-17.

4 Nyland H, Nilsen R. Localization of Fc $\gamma$ receptors in the human central nervous system. Acta Path Microbiol Immunol Scand 1982;(Sect C)90:217-21.

5 Ulvestad E, Williams K, Vedeler C, et al. Reactive microglia in multiple sclerosis lesions have an increased expression of receptors for the Fc part of IgG. 7 Neurol Sci 1994;121:125-31.

6 Vedeler C, Ulvestad E, Grundt I, et al. Fc receptor for IgG (FCR) on rat microglia. $\mathcal{F}$ Neuroimmunol 1994;49:19-24.

7 Ulvestad E, Williams K, Matre R, et al. Fc receptors for IgG on cultured human microglia mediate cytotoxicity and phagocytosis of antibody-coated targets. 7 Neuropathol Exp Neurol 1994;53:27-36.

8 Vedeler CA. Demonstration of Fc $\gamma$ receptors on human peripheral nerve fibres. $f$ Neuroimmunol 1987;15: 207-16.

9 Vedeler CA, Matre R, Kristoffersen E, et al. IgG Fc receptor heterogeneity in human peripheral nerves. Acta Neurol Scand 1991;84:177-80.

10 Vedeler CA, Nilsen R, Matre R. Localization of $\mathrm{Fc} \gamma$ receptors and complement receptors CR1 on human peripheral nerve fibres by immuno-electron microscopy. peripheraimmunol 1989;23:29-33.

11 Vedeler CA, Fitzpatrick-Kløve L. Receptors for immunoglobulin $G$ demonstrated on human peripheral nerve globulin $G$ demonstrated on human peripheral nerve
fibres by electron microscopy. Neurosci Lett 1990;115: fibres by

12 Vedeler CA, Scarpini E, Beretta S, et al. The ontogenesis of $\mathrm{Fc} \gamma$ receptors and complement receptors CR1 in human peripheral nerve. Acta Neuropathol 1990;80:35-40.

13 Vedeler CA, Conti G, Bannerman P, et al. Expression of genes encoding receptors for IgG (FcRIII) and for $\mathrm{C} 3 \mathrm{~b} / \mathrm{C} 4 \mathrm{~b}$ (Crry) in rat sciatic nerve during development and Wallerian degeneration. I Neurosci Res 1992;31:

4 Conti G, Vedeler C, Bannerman P, et al. Peripheral nervous system (PNS) expression of mRNAs encoding myelin proteins and FcyRIII during experimental allergic myelin proteins and Fc $\gamma$ III during experime

15 Panitch HS, Hirsch RL, Haley AS, et al. Exacerbations of multiple sclerosis in patients treated with gamma interferon. Lancet 1987;1:893-4.

16 Shabo AL, Maxwell DS. The subarachnoid space following the introduction of foreign protein: an electron microscopic study with peroxidase. $\mathcal{f}$ Neuropathol Exp Neurol 1971;30:506-24.

17 Wekerle H, Schwab M, Linington C, et al. Antigen presentation in the peripheral nervous system: Schwann cells present endogenous myelin auto-antigens to lymphocytes. Eur f Immunol 1986;16:1551-7.

18 Oldfors A. Macrophages in peripheral nerves. An ultrastructural and enzyme histochemical study on rats. Acta Structural and enzyme histoch

19 Watkins BA, Dorn HH, Kelly WB, et al. Specific tropism of HIV-1 for microglial cells in primary human brain cultures. Science 1990;249:549-53.

20 Band $\mathrm{H}$, Talwar GP. Effect of macrophage activators on the phagocytosis of mycobacteria by Schwann cells. f Neuroimmunol 1986;13:109-13.

21 Lowy I, Brezin C, Neauport-Sautes C, et al. Isotype regulation of antibody production: $T$-cell hybrids can be selectively induced to produce IgG1 and IgG2 subclassspecific suppressive immunoglobulin-binding factors. Proc Natl Acad Sci USA 1983;80:2323-7.

22 Varin N, Sautes C, Galinha A, et al. Recombinant soluble receptors for the $\mathrm{Fc} \gamma$ portion inhibit antibody production in vitro. Eur $\mathcal{F}$ Immunol 1989;19:2263-8.

23 van der Meche FGA, Schmitz PIM, the Dutch GuillainBarré study group. A randomized trial comparing intravenous immune globulin and plasma exchange in venous immune globulin and plasma exchange in Guillain-

24 van Doorn PA, Brand A, Strengers PFW, et al. High-dose intravenous immunoglobulin treatment in chronic inflammatory demyelinating polyneuropathy. Neurology 1990;40:209-12.

25 Debre M, Bonnet M-C, Fridman W-H, et al. Infusion of Fc $\gamma$ fragments for treatment of children with acute immune thrombocytopenic purpura. Lancet 1993;342: 945-9. 